\title{
Comparison of specific expression profile in two in vitro hypoxia models
}

\author{
GEOVANA CALVO-ANGUIANO ${ }^{1,2}$, JOSE J. LUGO-TRAMPE ${ }^{3}$, ALBERTO CAMACHO ${ }^{1,4}$, \\ SALVADOR SAID-FERNÁNDEZ ${ }^{1}$, ROBERTO MERCADO-HERNÁNDEZ ${ }^{5}$, VIVIANA ZOMOSA-SIGNORET ${ }^{1}$, \\ AUGUSTO ROJAS-MARTÍNEZ ${ }^{6,7}$ and ROCIO ORTIZ-LÓPEZ ${ }^{2,7}$
}

\author{
${ }^{1}$ Biochemistry and Molecular Medicine Department, School of Medicine; \\ ${ }^{2}$ Center for Research and Development in Health Sciences, Genomic Unit; \\ ${ }^{3}$ Genetic Department, School of Medicine; ${ }^{4}$ Center for Research and Development in Health Sciences, Neurometabolism Unit, \\ Universidad Autonoma de Nuevo Leon, Monterrey, Nuevo León 64460; \\ ${ }^{5}$ Science Exact Department, School of Biological Science, Universidad Autonoma de Nuevo Leon, Monterrey, \\ Nuevo León 66451; ${ }^{6}$ Center for Research and Development in Health Sciences, Experimental Therapies Unit, Universidad \\ Autonoma de Nuevo Leon, Monterrey, Nuevo León 64460; ${ }^{7}$ Tecnologico de Monterrey, School of Medicine \\ and Health Sciences, Monterrey, Nuevo León 64710, Mexico
}

Received August 24, 2017; Accepted March 15, 2018

DOI: $10.3892 /$ etm.2018.6048

\begin{abstract}
The microenvironment plays a fundamental role in carcinogenesis: Acidity and hypoxia are actively involved in this process. It is important to have in vitro models to study these mechanisms. The models that are most commonly referred to are the hypoxia chamber and the chemical induction [Cobalt (II) chloride]. It is not yet defined if these models are interchangeable if the metabolic effect is the same, and if the results may be compared in these models. In the present study, the response to the effect of stress (hypoxia and acidity) in both models was evaluated. The results indicated that in the chemical model, the effect of hypoxia appeared in an early form at $6 \mathrm{~h}$; whereas in the gas chamber the effect was slow and gradual and at $72 \mathrm{~h}$ there was an overexpression of erythropoietin $(E P O)$, vascular endothelial growth factor (VEGF), carbonic anhydrase 9 (CA9) and hypoxia-inducible factor $1 \alpha(H I F l \alpha)$. In addition to the genes analyzed by reverse transcription-quantitative polymerase chain reaction, the global expression analysis between both models revealed the 9 most affected genes in common. The present study additionally identified 3 potential genes (lysyl oxidase, ankyrin repeat domain 37, B-cell lymphoma 2 interacting protein 3 like) previously identified in other studies, which may be considered as universal hypoxia genes along with HIF1a, EPO, VEGF, glucose transporter 1 (GLUT1),
\end{abstract}

Correspondence to: Dr Rocio Ortiz-López, Tecnologico de Monterrey, School of Medicine and Health Sciences, CITES 3er Piso, Avenue I, Morones Prieto No. 3000 Poniente, Col. Los Doctores, Monterrey, Nuevo León 64710, México

E-mail: rortizl@itesm.mx

Key words: hypoxia, HIF1 $\alpha$, microenvironment, $\mathrm{pH}$
$C A 9$, and $L D H$. To the best of the author's knowledge, this is the first time that both hypoxia models have been compared, and it was demonstrated that the effect of hypoxia induction was time sensitive in each model. These observations must be considered prior to selecting one of these models to identify selective hypoxia genes and their effects in cancer.

\section{Introduction}

Carcinogenesis is a process where potential alterations in oncogenes, proto-oncogenes, conductive genes and loss in tumor suppressor genes accumulate over time (1). Nevertheless, recent evidence has shown that changes in the metabolism of cancer cells might be an important factor responsible for neoplastic development. In the Hanahan and Weinberg (2) model, the authors propose that changes in metabolism and in cellular microenvironment are important modulators of a tumor's sustainment and progression. Changes in the tissue microenvironment including lack of nutrients, hypoxia, and acidosis activate intracellular signaling pathways leading to a selective cell physiologic program to sustain adaptation to a new microenvironment (3). Also, recent reports have been identified that acidity modulates significantly the generation of metastasis (4). However, there is still a lack of knowledge regarding the potential role of hypoxia and acidity on intracellular transcriptomic phenotype.

During tumor development, the Hydrogen potential $(\mathrm{pH})$ plays a potential role in the cellular division, the normal physiological $\mathrm{pH}$ it is estimated at a range between of 7.1-7.2 (1). In this context, when tumor development occurs, this $\mathrm{pH}$ decreases; acidifying the microenvironment intra or extracellularly, an acid microenvironment is favored, promoting a metastatic cell phenotype $(5,6)$.

The normal atmospheric level of oxygen is $21 \%$, (normoxia) (7), hypoxia occurs when there is a decrease in 
oxygen tension below the critical level (1 to $2 \%$ ) (8). Cellular hypoxia can occur in both physiological conditions and in different pathological conditions (9), and cells adapt immediately by inducing the hypoxia-inducible factor $1 \alpha(H I F 1 \alpha)(10)$. The heterodimer HIFl $\alpha$ is composed of alpha and beta subunits. In normoxia conditions, HIFl $\alpha$ is constitutively expressed and degraded in a short period of time (11-14). Under a hypoxic scenario HIFl $\alpha$ regulates cellular homeostasis and systemic response by positive or negatively modulating the transcriptional activation of selective genes, including those involved in energetic metabolism [glucose transporter 1 (GLUT1)], angiogenesis [vascular endothelial growth factor $(V E G F)$ ], survival [erythropoietin $(E P O)], \mathrm{pH}$ maintaining [carbonic anhydrase 9 (CA9)], cell death (CASP3 and CASP7), and others that facilitate oxygen supply or metabolic adaptation to hypoxia (11).

To address the effect of hypoxia on cell physiology, two classical cellular micro-environmental models have been carried out. The first model uses a hypoxia sealed chamber containing a mixture of gases where oxygen is at 1 to $2 \%$. The second one uses a chemical agent, which is highly reactive with oxygen, for example, iron (deferoxamine); flavonoids, for example, quercetin; an inhibitor dependent of 2-oxoglutarate oxygenase; and transition metals, like cobalt (15). In fact, chemical induction with cobalt chloride $\left(\mathrm{CoCl}_{2}\right)$ is the chemical model most frequently used (16). The gas chamber and chemical models have been used interchangeably to evaluate the effect of hypoxia in different cellular environments. In general, we sought to identify networks of selective metabolic genes activated by both hypoxic models, cobalt chloride and chamber sealed by hypoxia, using microarray analysis. We hypothesized that chemical or cellular hypoxia could regulate time-dependent genes involved in cell viability, apoptosis, and cell proliferation.

\section{Materials and methods}

Cell culture and maintenance. We used the cell line Caco-2 [adenocarcinoma colorectal; American Type Culture Collection (ATCC), Rockville, MD, USA] in all assays. Caco-2 cell line was cultivated in Dulbecco's modified Eagle's medium (DMEM; Gibco; Thermo Fisher Scientific, Inc., Waltham, MA, USA) supplemented with $10 \%$ fetal bovine serum, $1 \%$ penicillin-streptomycin, and was maintained at $37^{\circ} \mathrm{C}$, with $5 \% \mathrm{CO}_{2}$.

Gas chamber with induced hypoxia. A total of 150,000 Caco-2 cells were seeded in each well, incubated for $24 \mathrm{~h}$ to allow their adhesion. The cultures were then placed into the gas chamber (Stemcell Technologies, Inc., Vancouver, BC, Canada). The chamber was closed and the gas mixture $\left(1 \% \mathrm{O}_{2}, 5 \% \mathrm{CO}_{2}\right.$ and $94 \% \mathrm{~N}_{2}$ ) was injected for $5 \mathrm{~min}$ (at a controlled pressure of 2 psi) to ensure equilibrium of the oxygen concentration in the cell medium, after which the chamber was sealed and finally placed in the incubator at $37^{\circ} \mathrm{C}$. Hypoxic treatment was maintained for $0,3,6,24,48$ and $72 \mathrm{~h}$.

Chemical hypoxia induction with cobalt chloride $\left(\mathrm{CoCl}_{2}\right)$. For chemical hypoxia 150,000 Caco-2 cells were seeded in each well in the 6-well plates, incubated for $24 \mathrm{~h}$ to allow their adhesion and $100 \mu \mathrm{M} \mathrm{CoCl}_{2}$ (Sigma-Aldrich; Merck KGaA,
Darmstadt, Germany) were added to the medium and were incubated for $0,3,6,24,48$ and $72 \mathrm{~h}$.

Acidosis assay. To simulate acidosis in our hypoxic model, the $\mathrm{pH}$ of the medium was determined by adding $25 \mathrm{mM}$ 4-(2-hydroxyethyl)-1-piperazineethanesulfonic acid (HEPES) or $25 \mathrm{mM} 3$-( $N$-morpholino) propanesulfonic acid (MOPS). Subsequently, the $\mathrm{pH}$ was measured using a SevenMulti standard potentiometer (Mettler Toledo, Greifensee, Switzerland), initially calibrated with reference buffer solutions (Hanna Instruments, Woonsocket, RI, USA), and was finally adjusted to $6.5,6.7$ or 6.9 with $1 \mathrm{M} \mathrm{HCl}$.

Cell viability assay. Once $\mathrm{pH}$ and hypoxia conditions were selected, cell viability in the Caco-2 cell line was evaluated, with the chemiluminescent assay using the Cell Titer Glo Luminescent kit (Promega Corporation, Madison, WI, USA). Caco-2 cells were seeded in 96-well plates in a density of 15,000 cells/well and were cultivated for $24 \mathrm{~h}$ at $37^{\circ} \mathrm{C}$ in $5 \% \mathrm{CO}_{2}$ to allow their adhesion. They were then exposed to $\mathrm{pH}$ and hypoxia protocols during $0,24,48$ and $72 \mathrm{~h}$ and the cell viability was measured. This method is based on the quantification of ATP in the culture, and the levels are directly proportional to the presence of metabolically active cells.

Apoptosis chemiluminescent assay. Apoptosis was determined using the Caspase-Glo ${ }^{\mathrm{R}}$ 3/7 Assay Protocol kit (Promega Corporation). This assay measured caspase $3 / 7$ activity and the luminescent signal that are directly proportional to the apoptosis level in the evaluated cells.

RNA extraction, reverse transcription-quantitative polymerase chain reaction ( $R T-q P C R)$. To evaluate the effect of cellular stress by hypoxia and acidity on cell metabolism, we carried out a Real-Time mRNA expression analysis of a panel of genes involved in hypoxia-metabolism: HIFl $\alpha, E P O$, GLUT1, VEGF, LDH and CA9 by qPCR and SYBR-Green using $G A P D H$ as gene normalizer. We previously performed an assay for the selection of the endogenous gene (data not shown) was made by the comparison of GAPDH, GPI and $E M C 7$ using a gene stability assay (17). Our results showed that compared to the GPI and EMC7 genes, the GAPDH gene was the most stable gene. Cultures were maintained under the hypoxia and acid protocols and total RNA was isolated using TRIzol reagent (Invitrogen; Thermo Fisher Scientific, Inc.), following instructions from the fabricators, followed by a treatment with DNAse (Qiagen, Inc., Valencia, CA, USA). RNA integrity and concentration was evaluated by spectrophotometry with Nanodrop 8000 (Thermo Fisher Scientific, Inc.).

cDNA was synthesized from $1 \mu \mathrm{g}$ of total RNA using High-Capacity cDNA Reverse Transcription kit (Applied Biosystems; Thermo Fisher Scientific, Inc.), following the fabricator's instructions. The primers for the metabolic genes and the constitutive gene were designed in accordance with the sequences from the database Gen Bank (Table I). The real-time PCR thermal cycler LightCycler 480 (Roche Diagnostics, Indianapolis, IN, USA) and the reagent SYBR-Green I Master (Roche Diagnostics) were used. All the qPCR reactions were triplicated and three independent assays were carried out. 
The expression analysis was carried out by the relative $2^{-\Delta \Delta \mathrm{Cq}}$ quantification method (18).

Microarrays analysis (expression profiles). The RNA, sample processing, microarray hybridization, and gene expression analysis were conducted using the GeneChip 3' IVT Express kit (Affymetrix; Thermo Fisher Scientific, Inc.). The hybridization mixture was prepared and applied to the GeneChip Human Genome U133 Plus 2.0 Array (Affymetrix; Thermo Fisher Scientific, Inc.), measuring $>43,000$ transcripts representing $>20,000$ human genes. Washing and scanning processes were realized in the Fluidics Station 400 and GeneChip Scanner 3000 7G, respectively, and preliminary data analysis was completed using Microarray Suite software version 5.0.0.032. Normalization was performed using robust microarray analysis and quantile normalization.

Statistical analysis. Data were compared using a two-way ANOVA (treatment and time) and Dunnet's test was performed to compare viability and apoptosis in all trials. The variables were previously normalized (Kolmogorov-Smirnov). The analysis was performed using SPSS software v20.0 (SPSS, Inc., Chicago, IL, USA). All graphs were done with GraphPad Prism v6.0 (GraphPad Software, Inc., La Jolla, CA, USA). All assays were performed in triplicate. Results are expressed as the mean \pm standard deviation.

\section{Results}

Viability assays in chemical and sealed gas chamber hypoxia models. To determine the effect of hypoxia on cell viability, cells treated with $\mathrm{CoCl}_{2}$ or maintained in the gas chamber were quantified as described. When comparing viability based on time and treatment, a highly significant difference was found in time $(\mathrm{F}=15.396, \mathrm{P}<0.01)$ and for the treatment $(\mathrm{F}=17.288, \mathrm{P}<0.01)$. We found a significant decrease in cell viability in cells treated with $\mathrm{CoCl}_{2}$ at $48 \mathrm{~h}$ and $72 \mathrm{~h}$ compared to the control without chemical hypoxia (Fig. 1A). In contrast, hypoxia-induced in sealed gas chamber shows a substantial increase in cell viability at a similar time frame to chemical hypoxia, 48 and $72 \mathrm{~h}$ (Fig. 1B).

Apoptosis evaluation in chemical and sealed gas chamber hypoxia models. The caspase 3/7 activity ratio was measured to evaluate apoptosis in both hypoxia models. The results of apoptosis displayed significant changes between the control at time $72 \mathrm{~h}(\mathrm{~F}=964.923, \mathrm{P}<0.01)$ and for the treatment of hypoxia chamber $(\mathrm{F}=1,154.081, \mathrm{P}<0.01)$. It was observed that chemically induced hypoxia does not promote apoptotic activation when compared to the normoxia control in all the times (Fig. 1C). We did find that hypoxia induced by the gas chamber decreased apoptosis significantly at $72 \mathrm{~h}$ compared to the normal control (Fig. 1D). This data suggests that a hypoxic environment induced by gas chamber incubation may have a severe effect on oxygen depletion leading to cell death and does not favor proliferation.

Evaluation of the effect of $\mathrm{pH}$ and $\mathrm{pH}+$ hypoxia on viability and apoptosis in both models of hypoxia. We evaluated the acidity effect in the chemical and sealed gas chamber
Table I. Primer sequence used in the quantification of the expression of genes sensible to stress.

A, Hypoxia sensitive genes

\begin{tabular}{ll}
\hline Gene & Sequence \\
\hline
\end{tabular}

$H I F 1 \alpha$
$\mathrm{F}$
$\mathrm{R}$
EPO
$\mathrm{F}$
$\mathrm{R}$
$C A 9$
$\mathrm{~F}$
$\mathrm{R}$
$V E G F$
$\mathrm{~F}$
$\mathrm{R}$
$G L U T 1$
$\mathrm{~F}$
$\mathrm{R}$
ATCCATGTGACCATGAGGAAATG TCGGCTAGTTAGGGTACACTTC

GGAGGCCGAGAATATCACGAC CCCTGCCAGACTTCTACGG

GGATCTACCTACTGTTGAGGCT CATAGCGCCAATGACTCTGGT

AGGGCAGAATCATCACGAAGT AGGGTCTCGATTGGATGGCA TCTGGCATCAACGCTGTCTTC CGATACCGGAGCCAATGGT

\section{$\mathrm{B}$, Endogenous gene}

\begin{tabular}{ll}
\hline Gene & \multicolumn{1}{c}{ Sequence } \\
\hline GAPDH & \\
$\mathrm{F}$ & ACAACTTTGGTATCGTGGAAGG \\
$\mathrm{R}$ & GCCATCACGCCACAGTTTC \\
\hline
\end{tabular}

GLUT1, glucose transporter 1; VEGF, vascular endothelial growth factor; HIF1 $\alpha$, hypoxia-inducible factor 1A; EPO, erythropoietin.

hypoxia models by setting three $\mathrm{pH}$ values: $6.5,6.7$ and 6.9 . An increase in cell viability was observed at 48 and $72 \mathrm{~h}$ when the cells were exposed to the most acidic $\mathrm{pH}(\mathrm{Ph} 6.7$ and 6.9), compared against normoxia conditions (Fig. 2A and $\mathrm{B})$. We also found that viability and apoptosis showed time-dependent significant changes $(\mathrm{F}=18.759, \mathrm{~F}=55.840$, $\mathrm{P}<0.01)$, whereas at $\mathrm{pH} 6.5$ there was a decrease in cell proliferation when compared to normoxia. This indicates that pH 6.5 significantly affects cell viability (Fig. 2A). We also found that changes in $\mathrm{pH}$ do not affect the number of apoptotic cells at 24,48 and $72 \mathrm{~h}$ when compared to normoxia (Fig. 2B).

Next, we determined cell viability in the $\mathrm{pH}+$ chemical hypoxia model. We found no changes at any of the three $\mathrm{pH}$ values analyzed (Fig. 2C). Finally, we observed that the $\mathrm{pH}+$ sealed chamber hypoxia model promotes an increase in viability at $\mathrm{pH} 6.9$ and 6.7 when compared to normoxia at $48 \mathrm{~h}$ (Fig. 2D). After $72 \mathrm{~h}$, we still found an increase in cell viability at $\mathrm{pH} 6.7$ and no changes at $\mathrm{pH} 6.9$ and 6.5 (Fig. 2D). These results reproduce, at least in part; those observed in the independent measurements of hypoxia or acidity and support the effect of $\mathrm{pH}$ on cell viability during hypoxia. 

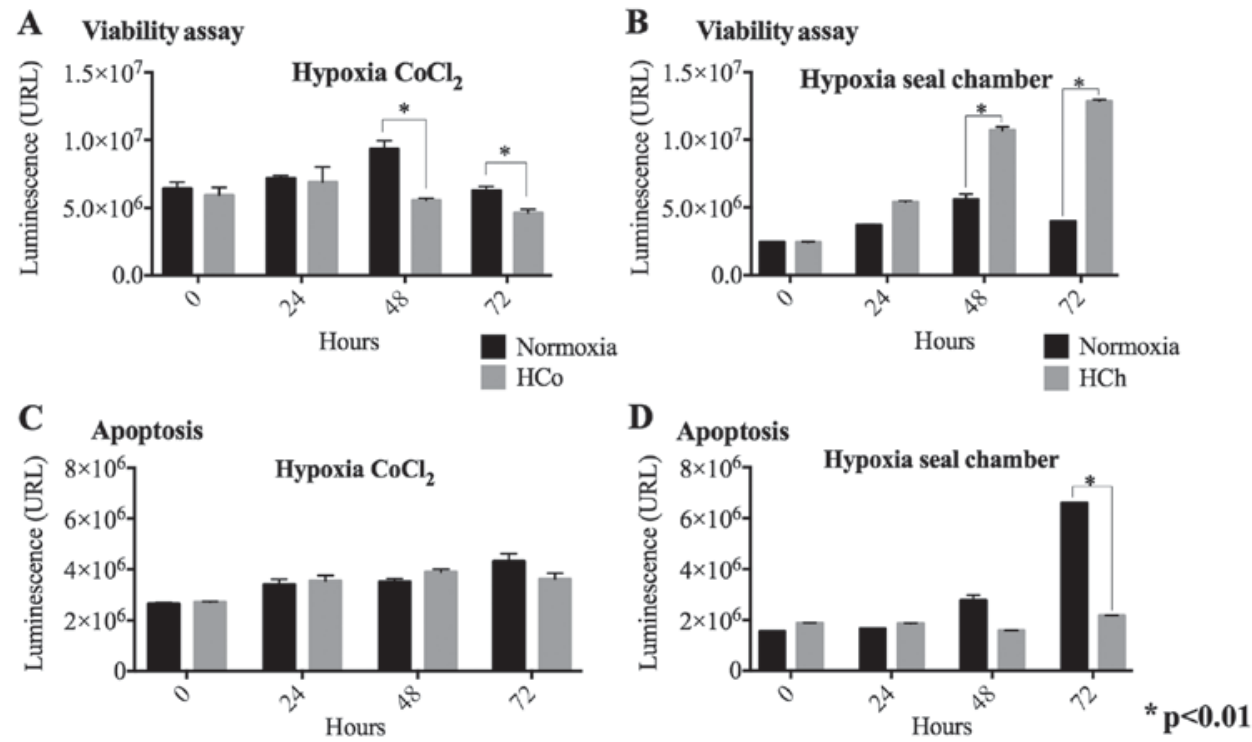

Figure 1. Cell viability and apoptosis under both models of hypoxia. (A) Chemical model and (B) Gas chamber. It is observed that in the (A) chemical model there is cell death starting at $48 \mathrm{~h}$ while in the (B) gas chamber model there is an increase in cell viability, compared to the control. There is the same cell death (apoptosis) in the (C) chemical model with respect to the normal control (statistical significance ${ }^{*} \mathrm{P}<0.01$ ), while the contrary occurred in the (D) cells maintained in the gas chamber at $72 \mathrm{~h}$.
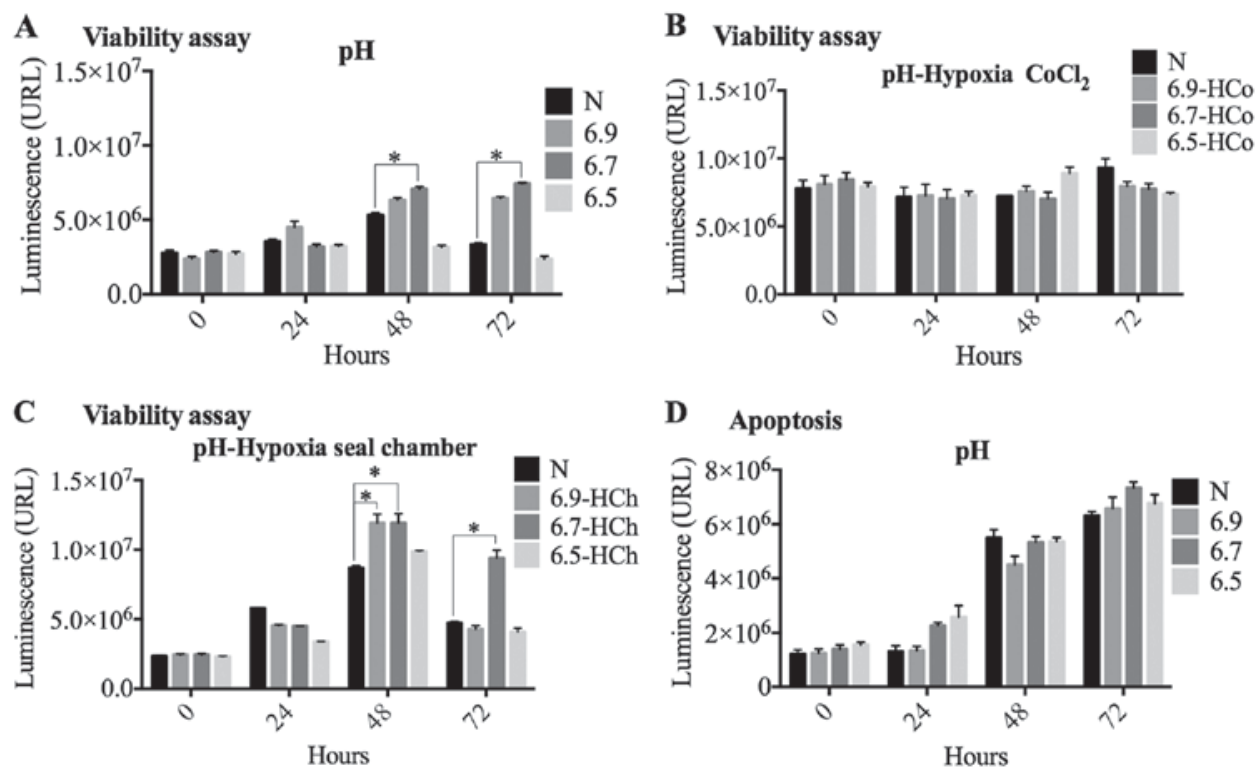

Figure 2. Acidity effect on cell viability. Cell viability was measured at different $\mathrm{pH}: 6.5,6.7$ and 6.9 in (A) standard (normoxia) culture conditions, (B) in chemically induced hypoxia, and (C) by gas chamber. (A) In normoxia conditions and (B) chemical model induced cell viability and behavior in cell viability has a pattern similar to the increase in plate confluence. (C) In the hypoxia induced by chamber an increase in viability at 48 or $72 \mathrm{~h}$ with pH 6.7 was observed. Apoptosis induction (D) in the Caco-2 cell line in normoxia conditions at acid pH increases with time but is independent of pH concentration (statistical significance "P<0.01). 6.9-Hco, Hypoxia chemically induced with $\mathrm{pH}$ 6.9; 6.7-Hco, hypoxia chemically induced whit $\mathrm{pH}$ 6.7; 6.5-Hco, hypoxia chemically induced with $\mathrm{pH} 6.5$; 6.9-Hca, hypoxia-induced in gas chamber with $\mathrm{pH}$ 6.9; 6.7-Hca, hypoxia-induced in gas chamber whit $\mathrm{pH}$ 6.7 and 6.5-Hca, hypoxia-induced in gas chamber with $\mathrm{pH} 6.5$.

Effect of $\mathrm{pH}$ on the expression of hypoxia response genes. To implement the standardization of the hypoxia model, we initially evaluated the effect of $\mathrm{pH}$ on six genes related to hypoxia response: HIFI $\alpha$, EPO, VEGF, GLUT1, CA9, and $L D H$. These results suggest that $\mathrm{pH}$ changes are not involved as genetic modulators of HIF1 $\alpha, E P O, V E G F$, GLUT1, CA9, and $L D H$ (Fig. 3).

Gene expression comparison in the two models of hypoxia. We evaluated the expression of the same six genes in two hypoxia models. When we compared the two models we observed that the hypoxia induced by $\mathrm{CoCl}_{2}$ promotes an acute time specific increase in gene expression at $6 \mathrm{~h}$ and later showed a decrease to control values (Fig. 4). Observations of the hypoxia-induced sealed gas chamber show a stable effect on gene expression displaying a lower, gradual and maintained elevation. At $72 \mathrm{~h}$, the effect is maintained and $H I F 1 \alpha, E P O$, and $C A 9$ are still overexpressed. Finally, the gene GLUT1 stands out in that it only maintains basal levels of expression in both models (Fig. 4). At 

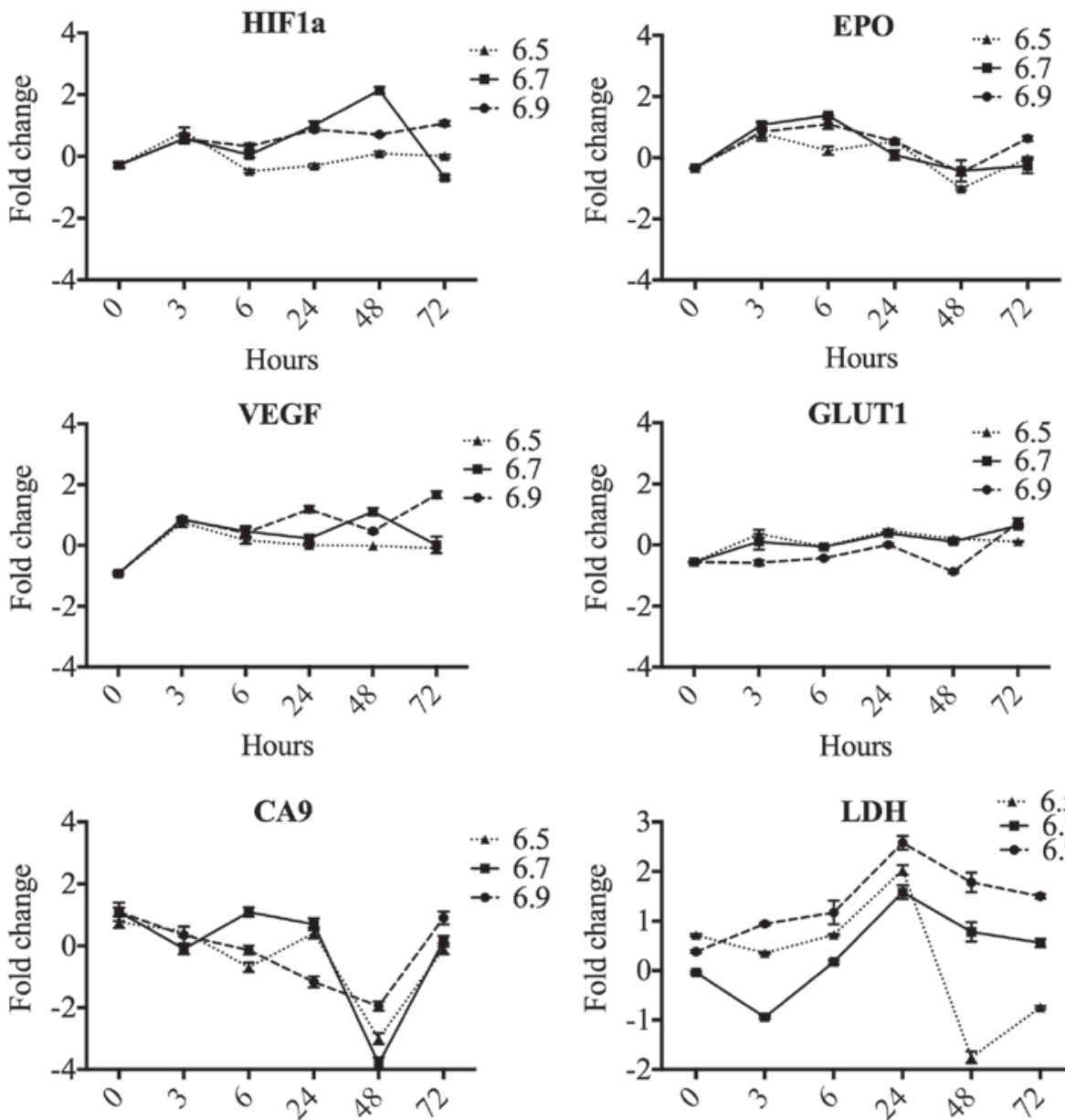

Hours

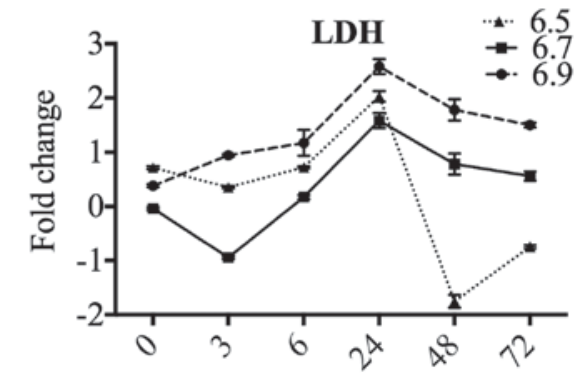

Hours

Figure 3. $\mathrm{pH}$ effect on the expression of six genes. Expression of HIFla, EPO, VEGF, GLUT1, CA9 and LDH in Caco-2 cells at different induction of pH measured by qPCR. Expression levels are normalized to expression of the housekeeping gene GAPDH.
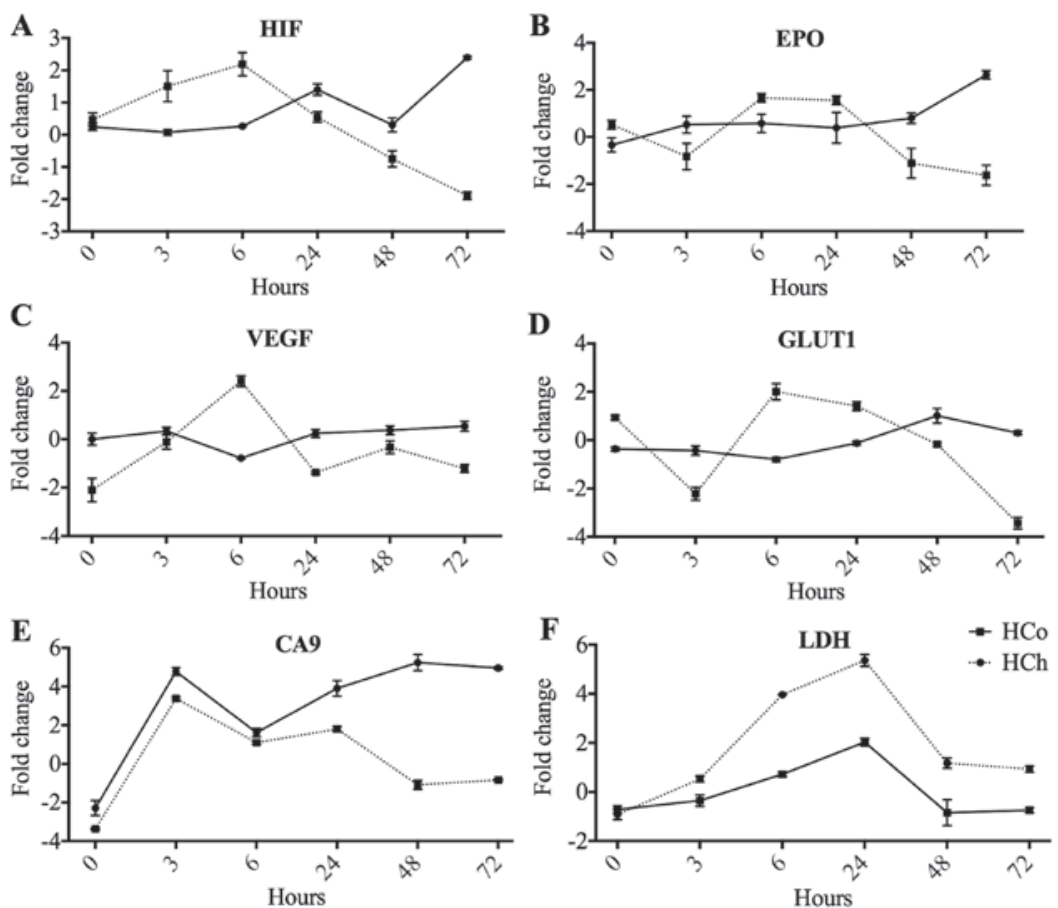

Figure 4. Expression of six genes in two hypoxia models. Expression of (A) HIF1a, (B) EPO, (C) VEGF, (D) GLUT1, (E) CA9 and (F) $L D H$ in Caco-2 cells at different induction of hypoxia measured by qPCR. Expression levels are normalized to expression of the housekeeping gene GAPDH. Hco, hypoxia chemically induced; Hca, hypoxia-induced in gas chamber. 
A

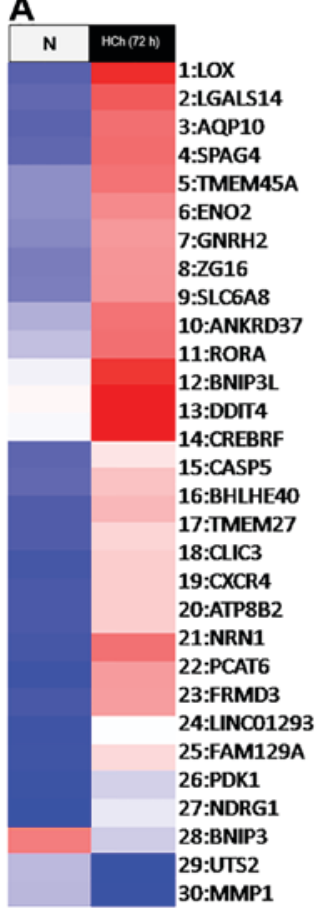

B

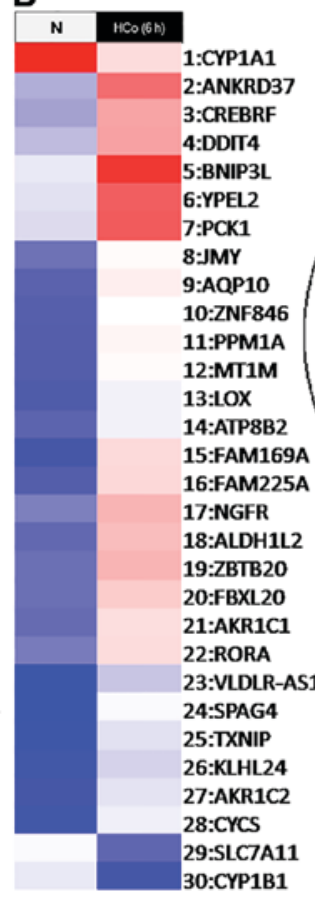

C

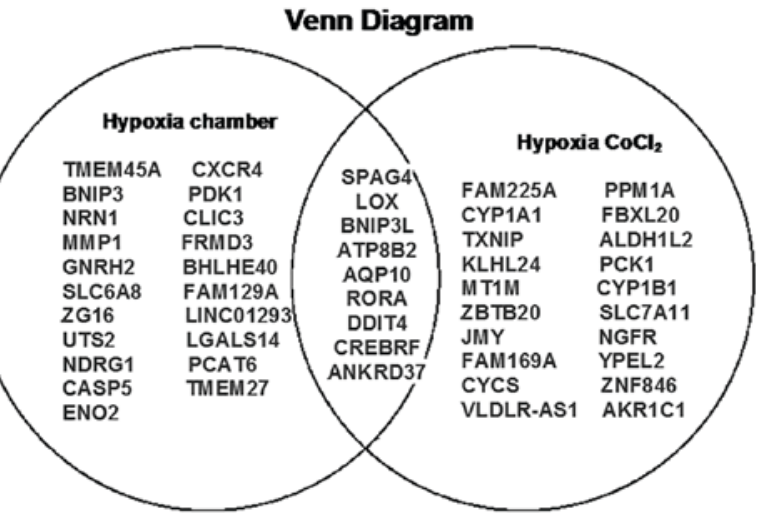

$\mathrm{N}=$ Normoxia, $\mathrm{HCh}=$ Hypoxia chamber, $\mathrm{HCO}=\mathrm{Hypoxia} \mathrm{CoCl}_{2}$

Figure 5. Gene expression levels in normoxic and hypoxic cells. (A and B) Heatmap of the genes from the hypoxia profile in both models. The color bar shows the fold change relative to the median expression of each gene across all conditions. The data shows the mean value of two independent experiments, and are $\log 2$ transformed. (C) Venn Diagram shows genes from hypoxia profile in both models with the deregulated genes obtained in microarray expression. Left: Signature hypoxia chamber shows 21 deregulated genes. Right: Signature hypoxia $\mathrm{CoCl}_{2}$ shows 21 deregulated genes. Intersection: Nine genes shared in both models.

this stage, our results suggest that chemical hypoxia modulates gene expression profile at $6 \mathrm{~h}$ whereas hypoxia-dependent chamber leads its major effects at $72 \mathrm{~h}$.

Finally, we found an early increase in HIF1 $\alpha$ expression that peaked at $6 \mathrm{~h}$ following a decrease later on (Fig. 4A). At $6 \mathrm{~h}$, we also identified an increase of EPO, VEGF, GLUT1 and $L D H$ genes (Fig. 4B-D and F). No significant changes were found in $C A 9$ (Fig. 4E).

Global gene expression profile in the two hypoxia models using microarrays. We used microarray analysis to determine the effect of global gene expression in the two hypoxia models: Chemical $(6 \mathrm{~h})$ and sealed chamber $(72 \mathrm{~h})$ induced hypoxia. We identified a gene expression profile for each model (Fig. 5A and B). The chemical hypoxia model promotes downregulation of 3 genes $(C Y P 1 A 1, C Y P 1 B 1$, and $C Y C S)$ and the overexpression of 27 genes: TXNIP, ALDH1L2, FAM169A, ZBTB20, RORA, CREBRF, FBXL20, LOX, ZNF846, YPEL2, PPM1A, FAM225A, NGFR, VLDLR-AS1, MT1M, ANKRD37, SPAG4, BNIP3L, ATP8B2, AKR1C1, SLC7A11, AQP10, $A K R 1 C 1, K L H L 24, D D I T 4, P C K 1, J M Y$. For the sealed gas chamber model, we found the subexpression of 2 genes: UTS2 and $M M P 1$ and the overexpression of 28 genes: LINC01293, CASP5, RORA, SLC6A8, ZG16, GNRH2, CREBRF, FAM129A, ANKRD37, CLIC3, ENO2, PCAT6, BHLHE40, BNIP3L, TMEM45A, TMEM27, DDIT4, FRMD3, CXCR4, NRN1, ATP8B2, SPAG4, LGALS14, AQP10, LOX, BNIP3, $P D K 1, N D R G 1$. We also observed that nine genes were shared between both models (SPAG4, LOX, BNIP3L, ATP8B2, AQP10, RORA, DDIT4, CREBRF, and ANKRD37) (Fig. 5C).

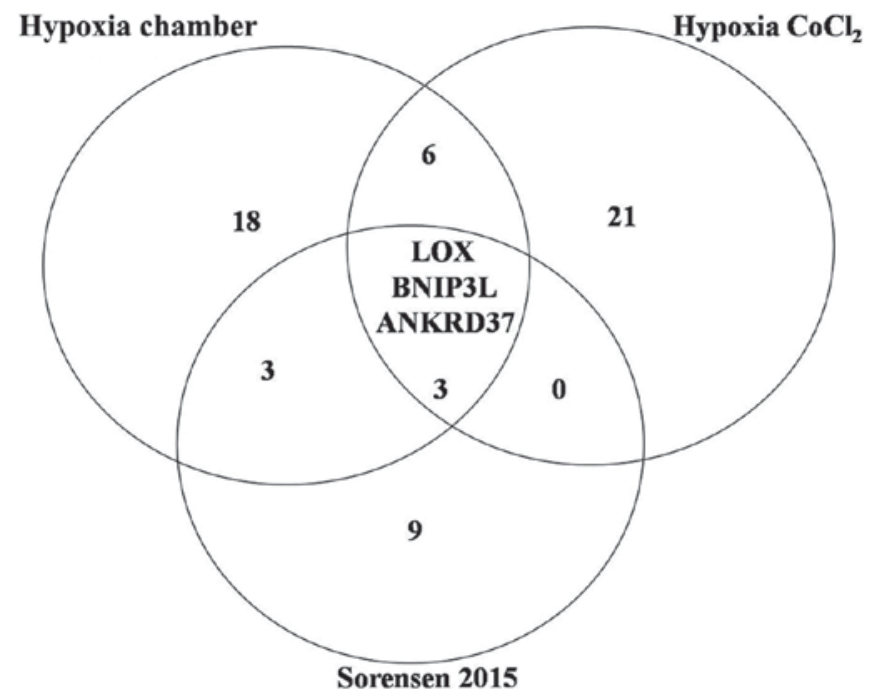

Figure 6. Deregulated genes. Venn diagram with the deregulated genes obtained in microarray expression. Left: Signature hypoxia chamber shows 30 deregulated genes. Right: Signature hypoxia $\mathrm{CoCl}_{2}$ shows 30 deregulated genes. Center: Signature Sorensen 2015 shows 15 deregulated genes. Intersection: Three genes, which are shared in three signatures.

On the other hand, we compared the gene signatures obtained from both models with the report of Sørensen et al (19) that reported a signature of 15 genes sensitive to hypoxia, finding 3 common genes in all the genetic signatures, suggesting that our data correlates with a universal genetic signature for the hypoxia profile (Fig. 6). 


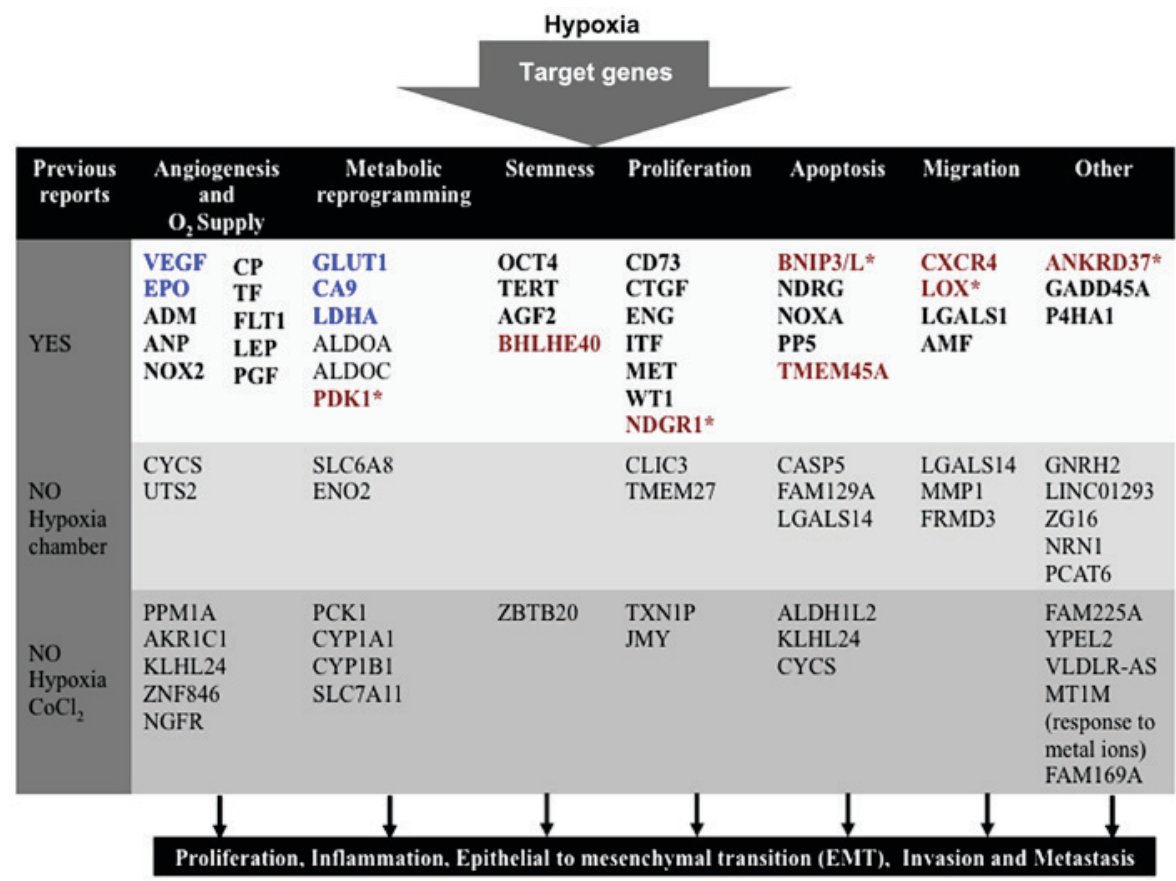

Figure 7. Genes regulated by hypoxia. Genes that are regulated by hypoxia and acidity in our work. The first line shows genes previously described. In blue: Genes traditionally referred to as genes of response to hypoxia; in red: A group of genes that have recently been considered as new hypoxia response genes; in the second line: Gas chamber model; and in the third line: Chemical model, we describe genes that were identified in this work and have not been previously reported.

\section{Discussion}

Experimental evidence has shown the effect of hypoxia induction in vitro using the technical strategies implemented in our study (20-23). In general terms, one of the best candidates to identify the hypoxia model is the evaluation of HIF1 $\alpha$ expression. However, additional potential candidates are emerging to validate sensor genes in hypoxia and its metabolic effect, but they are not yet validated $(13,24,25)$. In this study, we evaluated five target genes of HIF1 $\alpha$ along with parameters of viability and apoptosis in two models of hypoxia, widely cited in the literature and with the potential to be interchangeable. We found that both models show similarities in the final induction of hypoxia and show no significant differences. However, we identified selective time-dependent changes particularly related to the induction of HIF1 $\alpha$ as a response to hypoxia. In addition, when the expression of the rest of the genes is analyzed, a variable expression is observed in the different times evaluated. For example, at $6 \mathrm{~h}$ in the $\mathrm{CoCl}_{2}$ model, we found the highest expression of all the genes evaluated, followed by a low expression and tendency to reach normal values in later times, such as 48 and $72 \mathrm{~h}$. In contrast, the gas chamber model showed increased and gradual gene expression, which was maintained for up to $72 \mathrm{~h}$. This indicates that in the chemical model, the cells normalize the system rapidly at 3 to $6 \mathrm{~h}$ and in the hypoxia $\mathrm{CoCl}_{2}$ model the effect is rapidly reversed. On the other hand, in the gas chamber model, the cells slowly adapted to the change in a time-dependent manner and the effect was observed and maintained in response to hypoxia.

We propose that these observations must be considered when choosing one of this hypoxia models in order to define if the effect that is desired to quantify is analyzed from 3 to $6 \mathrm{~h}$ or even a more prolonged time, as was proposed recently (26).
One of the major achievements of our study is that we show, for the first time, a comparison in both chemical and chamber hypoxia models in different scenarios and identify a selective expression of the genes induced by HIFl $\alpha$. Our results also show that the effect of hypoxia induction is time sensitive and selective for each model. For example, a study reported by Danli Wu in 2011 using both hypoxia models quantifies HIFla as the only hypoxia marker in this scenario (16).

Potentials pathways mainly affected by hypoxia are glycolysis and oxidative phosphorylation (27). In this scenario cell viability assays may have technical limitations when the main goal is to quantify cell viability (28-30). For instance, no changes in oxidative phosphorylation and cellular ATP levels have been reported in in vitro trials trying to simulate conditions of lack of nutrients and hypoxia models (28-30). In our project we determined cell viability by using ATP quantification as a reliable marker of cell viability. However, we also agree that ATP levels can be altered by hypoxic conditions and this measurement might not be an indicator of cell viability so metabolic activity marker in cells.

Despite that our two hypoxia models show a selective time leading to HIFl $\alpha$ upregulation, we found 9 common hypoxia-inducible genes between both models, as observed in the Venn diagram (Fig. 5C). Our data correlate with previous results showing that hypoxia regulates similar metabolic pathways such as: Glycolysis, pyruvate metabolism, ATP synthesis, regulation of processes (catalytic activity, hydrolases, oxidoreductases) and other cellular processes like adhesion or transport (Fig. 7) $(23,24)$. In particular, Sørensen et al (19) in 2015 reported a 15 hypoxia-regulated genes signature as a universal hypoxia profile in various cancer cell types. Our data correlate with the LOX, ANKRD37, BNIP3L genes (Fig. 6), previously reported by Sørensen et al (19). This 
indicates that these three genes are highly regulated by the effect of hypoxia regardless of the hypoxia model induced with. At this stage, we propose that $L O X, A N K R D 37, B N I P 3 L$ genes might potentially be added as universal hypoxia genes along with HIFl $\alpha, E P O, V E G F, G L U T 1, C A 9$ and $L D H$ previously characterized.

In summary, in this study, we show that the effect of hypoxia is time-dependent regarding the hypoxia model used. Chemical induction simulates an acute hypoxia whereas chamber of gases maintains the effect of hypoxia in extended periods. These two hypoxia models share 9 susceptible genes and when comparing the two models of hypoxia with that reported by Sørensen et al (19), we found 3 genes (LOX, $A N K R D 37, B N I P 3 L)$ that could be considered as universal hypoxia genes along with HIF1 $\alpha, E P O, V E G F$, GLUT1, CA9, and $L D H$.

Our study opens a new research area showing the significant value of identifying potential oxygen sensors and key genes involved in metabolism and stress conditions during hypoxia. Finally, it might be required to study the expression and methylation of these genes to amplify the knowledge in this area and to better evaluate the effect of hypoxia in the mechanisms of cancer progression and metabolism of tumor cells.

\section{References}

1. Gatenby RA, Smallbone K, Maini PK, Rose F, Averill J, Nagle RB, Worrall L and Gillies RJ: Cellular adaptations to hypoxia and acidosis during somatic evolution of breast cancer. Br J Cancer 97: 646-653, 2007.

2. Hanahan D and Weinberg RA: Hallmarks of cancer: the next generation. Cell 144: 646-674, 2011

3. Joyce JA and Pollard JW: Microenvironmental regulation of metastasis. Nat Rev Cancer 9: 239-252, 2009.

4. Martínez-Zaguilán R, Seftor EA, Seftor RE, Chu YW, Gillies RJ and Hendrix MJ: Acidic $\mathrm{pH}$ enhances the invasive behavior of human melanoma cells. Clin Exp Metastasis 14: 176-186, 1996.

5. Griffiths JR: Are cancer cells acidic? Br J Cancer 64: 425-427, 1991.

6. Chiche J, Brahimi-Horn MC and Pouysségur J: Tumour hypoxia induces a metabolic shift causing acidosis: A common feature in cancer. J Cell Mol Med 14: 771-794, 2010.

7. Abaci HE, Truitt R, Luong E, Drazer G and Gerecht S: Adaptation to oxygen deprivation in cultures of human pluripotent stem cells, endothelial progenitor cells and umbilical vein endothelial cells. Am J Physiol Cell Physiol 298: C1527-C1537, 2010.

8. Solaini G, Baracca A, Lenaz G and Sgarbi G: Hypoxia and mitochondrial oxidative metabolism. Biochim Biophys Acta 1797: 1171-1177, 2010

9. Dayan F, Mazure NM, Brahimi-Horn MC and Pouysségur J: A dialogue between the hypoxia-inducible factor and the tumor microenvironment. Cancer Microenviron 1: 53-68, 2008.

10. Ke Q and Costa M: Hypoxia-inducible factor-1 (HIF-1). Mol Pharmacol 70: 1469-1480, 2006.

11. Weidemann A and Johnson RS: Biology of HIF-1alpha. Cell Death Differ 15: 621-627, 2008.

12. Jewell UR, Kvietikova I, Scheid A, Bauer C, Wenger RH and Gassmann M: Induction of HIF-1alpha in response to hypoxia is instantaneous. FASEB J: 2001.

13. Messineo S1, Laria AE1, Arcidiacono B1, Chiefari E1, Luque Huertas RM, Foti DP and Brunetti A: Cooperation between HMGA1 and HIF-1 contributes to hypoxia-induced VEGF and visfatin gene expression in 3T3-L1 adipocytes. Front Endocrinol (Lausanne) 7: 73, 2016.
14. Höpfl G, Ogunshola $\mathrm{O}$ and Gassmann M: HIFs and tumors-causes and consequences. Am J Physiol Regu 286: R608-R623, 2004.

15. Masoud GN and Li W: HIF-1ü pathway: Role, regulation and intervention for cancer therapy. Acta Pharm Sin B 5: 378-389, 2015.

16. Wu D and Yotnda P: Induction and testing of hypoxia in cell culture. J Vis Exp 12: 2899, 2011.

17. Eisenberg E and Levanon EY: Human housekeeping genes, revisited. Trends Genet 29: 569-574, 2013.

18. Livak KJ and Schmittgen TD: Analysis of relative gene expression data using real-time quantitative PCR and the 2(-Delta Delta C(T)) method. Methods 25, 402-408 2001.

19. Sørensen BS, Knudsen A, Wittrup CF, Nielsen S, Aggerholm-Pedersen N, Busk M, Horsman M, Høyer M, Bouchelouche PN, Overgaard J and Alsner J: The usability of a 15-gene hypoxia classifier as a universal hypoxia profile in various cancer cell types. Radiother Oncol 116: 346-351, 2015.

20. Wenger RH, Kurtcuoglu V, Scholz CC, Marti HH and Hoogewijs D: Frequently asked questions in hypoxia research. Hypoxia (Auckl) 3: 35-43, 2015.

21. Bensaad K, Favaro E, Lewis CA, Peck B, Lord S, Collins JM, Pinnick KE, Wigfield S, Buffa FM, Li JL, et al: Fatty acid uptake and lipid storage induced by HIF-1alpha contribute to cell growth and survival after hypoxia-reoxygenation. Cell Rep 9: 349-365, 2014.

22. Zhang YB, Wang X, Meister EA, Gong KR, Yan SC, Lu GW, Ji XM, Shao G, et al: The effects of $\mathrm{CoCl} 2$ on HIF-1 $\alpha$ protein under experimental conditions of autoprogressive hypoxia using mouse models. Int J Mol Sci 15: 10999-11012, 2014.

23. Chiche J, Ilc K, Laferrière J, Trottier E, Dayan F, Mazure NM, Brahimi-Horn MC and Pouysségur J: Hypoxia-inducible carbonic anhydrase IX and XII promote tumor cell growth by counteracting acidosis through the regulation of the intracellular pH. Cancer Res 69: 358-368, 2009.

24. Zuo J, Wen J, Lei M, Wen M, Li S, Lv X, Luo Z and Wen G: Hypoxia promotes the invasion and metastasis of laryngeal cancer cells via EMT. Med Oncol 33: 152016.

25. Guimarães TA, Farias LC, Santos ES, de Carvalho Fraga CA, Orsini LA, de Freitas Teles L, Feltenberger JD, de Jesus SF, de Souza MG, Santos SH, et al: Metformin increases PDH and suppresses HIF-1 $\alpha$ under hypoxic conditions and induces cell death in oral squamous cell carcinoma. Oncotarget 7: 55057-55068, 2016.

26. Zeng HL, Zhong Q, Qin YL, Bu QQ, Han XA, Jia HT and Liu HW: Hypoxia-mimetic agents inhibit proliferation and alter the morphology of human umbilical cord-derived mesenchymal stem cells. BMC Cell Biol 12: 32, 2011.

27. Li J, Zhang D, Ward KM, Prendergast GC and Ayene IS: Hydroxyethyl disulfide as an efficient metabolic assay for cell viability in vitro. Toxicol In Vitro 26: 603-612, 2012.

28. Depoix C, Barret LA, Hubinont C and Debieve F: Viability of primary term cytotrophoblast cell culture in normoxia and hypoxia. Mol Hum Reprod 19, 29-34 2013.

29. Jose C, Bellance N and Rossignol R: Choosing between glycolysis and oxidative phosphorylation: A tumor's dilemma? Biochim Biophys Acta 1807: 552-561, 2011.

30. Rodríguez-Enríquez S, Carreño-Fuentes L, Gallardo-Pérez JC, Saavedra E, Quezada H, Vega A, Marín-Hernández A, Olín-Sandoval V, Torres-Márquez ME and Moreno-Sánchez R: Oxidative phosphorylation is impaired by prolonged hypoxia in breast and possibly in cervix carcinoma. Int $\mathrm{J}$ Biochem Cell Biol 42: 1744-1751, 2010.

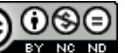

This work is licensed under a Creative Commons Attribution-NonCommercial-NoDerivatives 4.0 International (CC BY-NC-ND 4.0) License. 